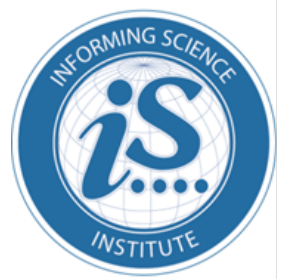

Proceedings of the Informing Science + Information Technology Education Conference

An Official Publication

of the Informing Science Institute

InformingScience.org

InformingScience.org/Publications

June 30 - July 4 2019, Jerusalem, Israel

\title{
THE BENEFITS AND CHALLENGES OF LIVING, TEACHING AND WORKING IN TODAY'S DIVERSE WORLD
}

Henry O’Lawrence
College of Health and Human Services, California State University, Long Beach, CA, USA hnry ren@outlook.com

\begin{abstract}
Aim/Purpose

The purpose of this report is to provide an understanding of cultural diversity in today's global economy and to understand what shapes our identities and what influences our behavior.

Background

Culture is the way of functioning in today's world and it refers to the shared language, beliefs, values, norms, behaviors, and material objects that are passed down from one generation to the next. Cultural diversity helps individuals recognize and respect the stewpot of today's world and promoting cultural diversity and cultural competency helps individuals define and respect the diversity that encompasses today. Cultural competence also helps individuals embrace values and cultural nuances that are not necessarily akin to the one's the individual possesses. Individuals interact with others to build bridges to trust, respect, and understanding across cultures. Furthermore, diversity makes the world a more interesting place to live, as people from diverse backgrounds contribute language, new ways of thinking, new knowledge, and different experiences.
\end{abstract}

Methodology

A non-systematic literature review by way of reviewing articles that were found in many of major databases under the terms "Diversity in the workplace" since the year 2010 was conducted.

Findings This study identified major findings that would help individuals shape the diversity encountered and provides an avenue toward unity.

Keywords diversity in the workplace, cultural diversity, socio-cultural differences, cultural differences, ethnicity

Accepted by Executive Review by Editor Eli Cohen | Received: February 24, 2019 | Revised: May 12, 2019| Accepted: May 13, 2019.

Cite as: O'Lawrence, H. (2019). The benefits and challenges of living, teaching and working in today's diverse world. Proceedings of the Informing Science and Information Technology Education Conference, Jerusalem, Israel, pp. 495-499 Santa Rosa, CA: Informing Science Institute. https://doi.org/10.28945/4355

(CC BY-NC 4.0) This article is licensed to you under a Creative Commons Attribution-NonCommercial 4.0 International License. When you copy and redistribute this paper in full or in part, you need to provide proper attribution to it to ensure that others can later locate this work (and to ensure that others do not accuse you of plagiarism). You may (and we encourage you to) adapt, remix, transform, and build upon the material for any non-commercial purposes. This license does not permit you to use this material for commercial purposes. 


\section{INTRODUCTION}

Cultural diversity helps individuals to recognize and respect others; it is a system of beliefs and behaviors that recognize and respect the presence of all diverse groups in an organization or society, acknowledges and values the socio-cultural differences, and encourages and enables continued contribution within an inclusive cultural context which empowers all within the organization or society . Having cultural diversity integrated into the workplace means that there is a diverse group of individuals working in an organization. According Amadeo (2019), cultural diversity in the workplace is when population differences are well represented in a workplace. People with various backgrounds have different perspectives and their contribution allows the group to look at problems from all angles which often result in innovations. This should be valued in the corporate philosophy and be integrated into company practices. Federal laws in the U.S. prohibit workplace discrimination in the areas of age, disability, national origin, race, religion, and gender. The Equal Employment Opportunity Commission promotes equal opportunity and handles complaints about workplace discrimination.

By improving an understanding of cultural differences as agents of change, individuals will need to convey respect towards all employees and have an understanding of how culture impacts behavior; it will improve overall job performance, enable an open mind, and broaden everyone's knowledge. Having culture integrated throughout the workplace can bring many benefits to an organization and companies will see an improvement in the workplace if cultural diversity exists throughout the work environment. Having a good workplace culture in an organization can bring the benefit of improved productivity of employees, and such improvement in productivity is a result of employees having a better connection with everyone in the workplace. According to Brookins (2018), employees who understand their workplace culture are able to have a better grasp of their goals and are more in tune with the needs of their managers, other employees, and customers. Furthermore, allowing for a culturally diverse work environment can provide individuals with the opportunity to become openminded and learn about other cultures and traditions. Diverse workplaces allow for the exposure of new skills and new approaches to work that can spawn new ideas that would create organizations that are receptive and exposed to different beliefs, ideas and opinions.

\section{FACTORS CONTRIBUTING TO Why Diversity SHOULd BE A CONCERN}

The Equal Employment Opportunity Commission (EEOC) protects individuals from being discriminated against, and anyone in any workplace must be treated equally and respectfully, regardless of their background or sexual preference. The U.S. Equal Employment Opportunity Commission enforces federal laws prohibiting workplace discrimination, and the employment section of the Civil Rights Act of 1964, known as Title VII, prohibits discrimination based on race, color, national origin, sex, and religion, and also prohibits employers from retaliating against any employee who exercises his or her rights under Title VII. Today, the EEOC enforces federal anti-discrimination statutes and provides oversight and coordination of all federal equal opportunity regulations, policies, and practices. By understanding our cultural differences, communication is a necessity in the workplace and sometimes a lack of an understanding can be a barrier that causes delays in the effectiveness of good productivity at work. It is therefore very important to find an effective way of communicating with other employees to ensure information is being retrieved effectively, ultimately resulting in the desired end result. To this end, understanding the importance of communication is very important and it is the best way to incorporate solutions to ease communication barriers, including using visual references such as sign languages or gesture/non-verbal communication (Tbirnbaum, 2017).

People from different backgrounds can contribute in the decision-making process by including their ideas in the discussion by keeping an open mind about ideas coming from a diverse perspective that could bring an excellent quality of work to fruition. Allowing inclusiveness in the workplace brings 
the best of out each individual. Bisk (2019) suggested that savvy businesses of all sizes are realizing the necessity of breaking into the global marketplace and would like to expand into international markets or to utilize global partners which makes it essential to have the relationships with the people they will be establishing the business partnership with. Therefore, it is beneficial to have members who understand and appreciate the culture of the country they plan to expand to. According to Cohn \& Caumont (2016), diversity should be a concern based on the following data:

- Americans are more racially and ethnically diverse than in the past. By the year 2055, there will not be a racial majority

- Asia has replaced Latin America as the biggest source of new immigrants to the U.S.

- America's demographic changes are shifting the electorate and American politics

- Millennials (born after 1980) are the new generation to watch

- Women's role in the labor force and leadership positions has grown dramatically

Individuals in today's society have lives that revolve around multicultural inputs without knowing or noticing it, and one third of the American population is multicultural consisting of many ethnic backgrounds, including but not limited to Latino, Asian, Native American, Middle Eastern, Pacific Islander, and African heritage. In today's multicultural United States, approximately, 381 languages are spoken or signed; religious minorities include 2.6 million of Jewish descent, 1.3 million Muslims, 1 million Buddhists, and one-half a million Hindus. Also, there are other people who identify themselves as Lesbian, Gay, Bi, Trans (LGBT) that are now gaining increasing visibility; and, approximately19\% of Americans have disabilities (Hays, 2013). Diversity in today's world is also based on the following categories:

- Professional Diversity - differences of perspectives and values in professional training

- Environmental Diversity - environmental factors, weather, transportation, urban vs. rural, island vs. mainland...

- $\quad$ Socio-Economic Diversity - dollars and resource access

- Educational Diversity - level of education/value of education

- $\quad$ Age Diversity - with today's aging workforce 4 generations are often present in workplace

- $\quad$ Racial/Ethnic - People of color/differing background

- Disability - "The U.S. government encourages the hiring of people with physical, mental or emotional disabilities through federal laws and by making funding available to companies to employ these workers. Even so-called invisible disabilities, such as depression, dyslexia and fibromyalgia, require workplaces to provide reasonable accommodations" (Ngwabi, 2017, para. 6).

Diversity is the wide range of differences that exist among people, such as visible characteristics and less obvious characteristics, while inclusion is a work environment where everyone can participate and is valued regardless of differences. Also, equity is just and fair inclusion into a society in which all can participate, prosper, and reach their full potential. Equity gives all people a just and fair shot in life despite historic patterns of exclusion. It is therefore very important that we learn how to manage diversity by identifying common ground, invest in professional development, improve team and organizational decision making and adopt the systems approach to ensure that diversity management and inclusion are built into the culture.

\section{TRAINING NEEDED IN TODAY'S WORLD}

Non-privileged (minorities) members are socialized to be aware of the lines separating those who have privilege and those who do not, and it is easier to perceive cultural influence when there is a contrast. Unfortunately, most of us learn to interact with each other by trial and error. There are 4 levels of diversity training and they are: 
- Legal awareness training focuses on the legal implications of discrimination. (Org.)

- Cultural awareness training builds a greater understanding of widely varying cultural backgrounds. (Group.)

- Sensitivity training "sensitizes" people to differences and how words and behaviors are seen by others. (Interpersonal)

- Values readjustment "appreciated" rather than "tolerating" diversity (Intrapersonal)

Our pigmentation has definitely acquired a social meaning that needs to be considered from a social perspective, and many in America and other dominant cultures have gone through discrimination because their skin color was deemed too dark. For instance, Brazil has 134 categories of skin colors (Blackness), while the U.S. and other countries only have a few. It is evident that many individuals from all walks of life have suffered extreme embarrassment and worse by not being aware of the cultural differences, not only from country to country but also within what the world considers one of the greatest countries, America.

\section{CONCLUSION AND RECOMMENDATIONS}

The essential knowledge of our world of diversity is that relationship mistakes are difficult to correct because the people we are dealing with often pull away. We all have biases and we are hardwired to categorize and make generalizations based on categories which frequently turn into stereotypes; the fact remains that we do not all belong to dominant cultural groups and when bias is reinforced by powerful groups and social structures, the results are systems of privilege and oppression. These systems of privilege and oppression have been around so long and they have names such as:

- $\quad$ Racial bias + power $=$ racism, ethnocentrism

- National bias + power $=$ imperialism, colonialism

- Christian bias + power $=$ anti-semitism

- Age bias + power $=$ ageism

- Disability bias + power $=$ ableism

- $\quad$ Class bias + power $=$ classism

- $\quad$ Sexual orientation + power $=$ heterosexism

- Gender bias + power $=$ sexism

Therefore, individuals have to continue to build relationships with people from other cultures by making a conscious decision to establish friendships with people from other cultures. Today's workers/individuals need to feel comfortable in situations where they will meet people of other cultures and one must also learn to examine one's own individual biases about people from other cultures. In order to survive and prosper in today's world, everyone must learn how to ask questions about their cultures, customs, and views, read about other people's cultures and histories, and most importantly listen to people tell their stories.

\section{REFERENCES}

Amadeo, K. (2019). Cultural diversity in the workplace: How diversity at work makes more money for you. Retrieved from: https://www.thebalance.com/cultural-diversity-3306201

Bisk, B. (2019). Why understanding cultural differences are vital for businesses. Retrieved from: www.notredameonline.com/resources/intercultural-management/why-understanding-cultural-differencesis-vital-for-businesses/\#.XAic6GhKiUk

Brookins, M. (2018). The advantages of workplace culture in an organization. Retrieved from https://smallbusiness.chron.com/advantages-workplace-culture-organization-2951.html 
Cohn, D. \& Caumont, A. (2016). 10 demographic trends that are shaping the U.S. and the world. Pew Research. Retrieved from https://www.pewresearch.org/fact-tank/2016/03/31/10-demographic-trends-that-areshaping-the-u-s-and-the-world

Hays, P. A. (2013). Connecting across cultures: The helper's toolkit. Thousand Oaks, CA: Sage Publishing.

Ngwabi, R. D. C. (2017). Forms of diversity in the workplace. Retrieved from http://smallbusiness.chron.com/forms-diversity-workplace-23105.html

Tbirnbaum. (2017). Equal employment opportunity commission. Retrieved from https://www.law.cornell.edu/wex/equal employment opportunity commission

\section{BIOGRAPHY}

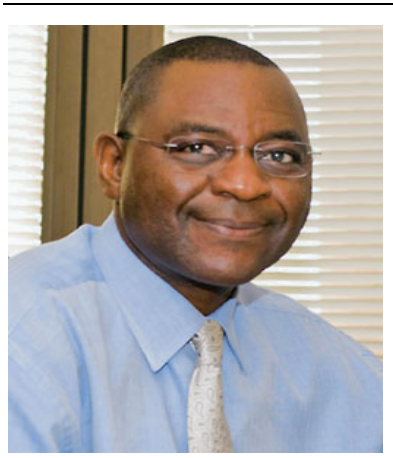

Henry O'Lawrence is a professor in the College of Health and Human Services at California State University Long Beach. Dr. O'Lawrence is a researcher and author of global health issues and a consultant in global risk management, assessment and prevention strategist for noncommunicable diseases; with over 15 years of professional leadership experience in human re development/corporate training, emergency services administration, program evaluation and assessment, public policy administration, research and data analysis, academics and curriculum development. 